\title{
Health Care Provider's Support from Mothers in NICU: A Focused Ethnography Study
}

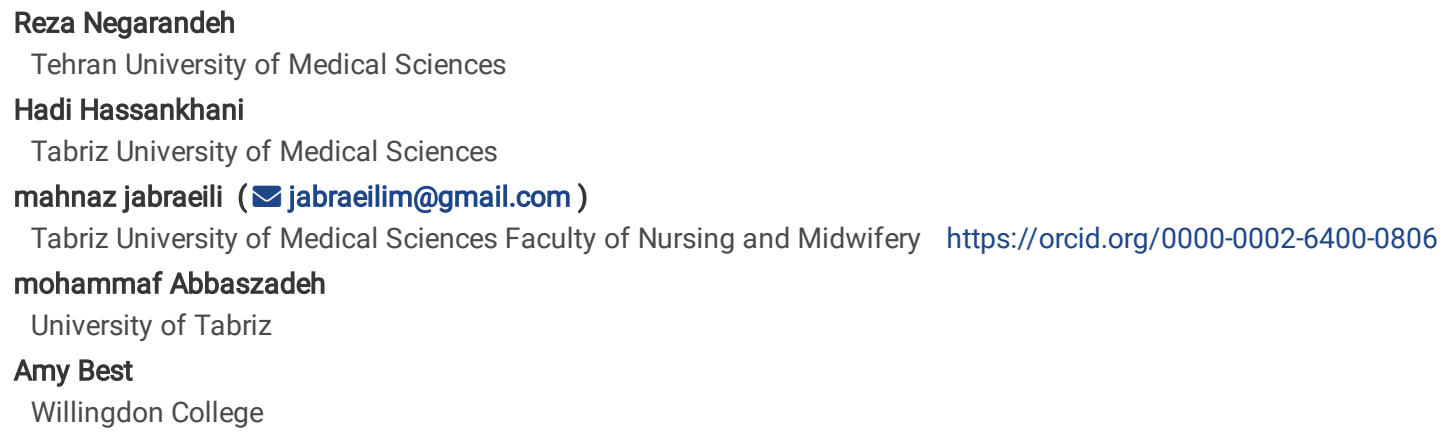

Version of Record: A version of this preprint was published at BMC Pregnancy and Childbirth on July 21st, 2021. See the published version at https://doi.org/10.1186/s12884-021-03991-3. 


\section{Abstract}

Background: Mothers of premature infants in the neonatal intensive care unit (NICU) have complex needs and require a significant amount of support during the NICU admission. However, little is known about mothers support needs in the NICU. The aim of study was to explore mothers and health staff experiences and care practices meeting support needs of the mothers in the NICU.

Methods: A focused ethnographic approach was adopted. Observation and interviews with 21 mothers, 18 nurses and 5 physicians were undertaken over a seven month period. Qualitative data analysis was conducted using the Roper and Shapira (2000) five-step framework.

Result: Two main themes of "failure to meet the support needs of mothers" (Subthemes: failure to accompany the mother in care, assigning monitoring and care to the mother, inadequate sharing of medical information) and "supporting the mothers in certain circumstances" (Subthemes: reassuring the mother, supporting mothers with reduced functional capacity, providing information) were obtained.

Conclusion: This study showed that the mothers were supported by the staff, particularly while mothers were in serious need of support. However, the staff considered the treatment and care of the infant as their main professional duty and mothers support was provided when they had the opportunity to support.

\section{Background}

The Neonatal Intensive Care Unit (NICU) is a health care unit that provides intensive and specialized therapeutic care for complicated infants [1]. Most premature infants, and full-term with special care such as infants with cesarean section, congenital anomaly, maternal diabetes and hypertension, necrotizing enterocolitis often require care in the NICU [2].

According to previous studies, Mothers experienced a moderate level of stress and anxiety during hospitalization of their infant [3-5]. The impact of an infant hospitalisation on maternal mental health is significant. Mothers are at increased risk of postpartum depression, anxiety and post-traumatic stress disorder [2].

The NICU environment is perceived by mothers as unfamiliar, terrifying, horrible and highly technical [6]. Mothers with an infant in the NICU can feel a loss of control and disconnect from their infant. These factors can present challenges that affect the parenting role such as delayed maternal attachment and reduced capacity for emotional bonding [7]. Parents experience considerable stress, distress, and difficulty maintaining their caregiver role [8]. Furthermore, the inability to fulfil this intrinsic parental role can result in anxiety and acute grief [9]. Suitable management of these emotions should be done by a trained nurse, giving information, helping to the mother for participate in caring of infant can help reduce stress [10].

Studies conducted in Iran show that, ability to talk daily with the health worker team, feeling that the hospital staff is taking good care of the patient, knowing what will happen to the patient, providing answers accurate and truly questions, were among the most important needs of mothers [11]. A systematic review in Iran showed that from the parents' point of view, the need for assurance, awareness, closeness, support and finally comfort was of the most important needs of parents [12]. Generally, the need for support is one of the main findings of studies conducted in Iran on the experiences of parents of premature infants admitted to the neonatal intensive care unit [11, 13-15]. In order to minimize the side effects of immediate infant's hospitalization on the mother-child relationship, requires psychological support services for maternal infants upon admission [14]. The studies show that supporting the parents decrease the anxiety, increasing awareness, growth of "self-confidence to their capabilities" in taking care of their infant [16] and finally, results in the reduction of hospitalization period of the infant and also increases the parents' satisfaction [17]. Therefore, it is essential that health care workers provide adequate support to help parents cope with the stress of infant hospitalization and improve their ability and confidence in the care of infants [18]. Given that nurses are care provider, they have a critical role in providing this support [19].

The cultural norms of care environments can affect maternal experiences and their support needing as well as staffs roles in the NICUs across different countries [20]. Most of the studies conducted in Iran are related to mothers' experiences in NICU [7, 14, and 21] and there is not enough information about the experiences of nurses and mothers about maternal support needing and the quality to meet these needs in NICU. The aim of study was to explore mothers' support needs and experiences in the NICU and staffs' perspective and care practices supported these needs.

\section{Methods}

The study setting was a NICU (level II) in Tabriz, Iran, Which is the main pediatric' referral center in the East Azarbaijan Province, in the North West of Iran. In this unit, admit stable full-term and premature neonates.

The physical space of the level two NICU consisted of a large hall equipped with 24 incubators. There was an average of three nurses on each shift, which provided nurse patient ratio of 1:5-8.

The mothers who their infants were hospitalised in NICU (level II) least one week and mother had presence continues in bed infants, and nurses that had at least 6 months' work experiences in NICU and physicians who were involved in the care of these infants were enrolled in the study. At the beginning of study, the principal investigator ( $\mathrm{PI}$ ) explained the goals of the study were to participants (mothers \& staffs) and asked them to read and sign the written consent. 
Descriptive, focused and selective observation was performed. The objective of descriptive observations was aware of the variety of events that occur during a usual day. For example, in this study, PI sat in the chairs in the unit and tried to describe everything she saw: the patients' admission, the procedure of evaluation, the comments made by mothers, and actions of the NICU staffs. In focused observation, collaborative observation [22] approach was used at the bedside of the neonate the researcher observes while also participating in care. mothers' observation was while the mother caring for infants and staff observation was during their interactions with mothers were close enough to ask the nurse or mother questions if necessary to clarify why the work was done.

When observation, in addition to verbal behaviors, non-verbal behaviors were also considered. Selective observation was typically focused on a specific feature of the activity. Behaviors (smiling, talking, etc.) Participants' actions (touching, time spent with the patient).

The interview began with an open-ended question. Nurses were first asked to "describe their experiences of supporting mothers in neonatal care." This was then followed up with questions such as "what do you think about supporting mothers?" "What kind of caring support do you think mothers need?" "Are there opportunities and constraints for cares to support mothers with neonates?" "How do you meet the needs of supporting mothers with neonate?" Mothers on the other hand were first asked to "share their experiences of support from nurses in their neonatal care." This opening question was followed by others such as "what problems do you face while participating in infant care?", "Who do you see when you have a care problem?" "What help do you receive from nurses about neonatal care?" "How do staffs provide you with the information you need?" "What do you expect nurses to do to support you?"

\section{Data analysis}

Data analysis began at the same time as data collection. Analysis of the data was conducted using Roper and Shapira's [22] 5-step Framework. The first step was coding. All field notes and formal and informal interviews were coded, interviews were reviewed and re-read several times to gain an overall understanding. The texts were then analysed word by word, line by line and paragraph by paragraph. The data was divided into small pieces and subsequently words or groups of words were identified and assigned a code in the coding step. The second step was sorting for patterns. Similar codes were put into a group or category called basic concepts. These concepts were then grouped in similarity to form sub-themes. These sub-themes were also incorporated into the main themes. The third step was identification of outliers where negative cases that did not match the study findings were identified and analysed in the data. The fourth step was generalizing. Constructs and theories of the findings were compared with existing studies and theories. The fifth step was memoing. Memos were reflections that occur during all stages of data collection and analysis and provide the basis for deep and meaningful understandings of your data. For example: The nurse said in the interview that mothers do not need help to change diapers and often do,

Memo: Do mothers also have this opinion? In the interview, mothers should be asked about this issue. Analysis of the data was conducted by the primary author and verified by a research team. The research team included two faculty expert in qualitative research, and a faculty sociologist expert in ethnography.

The study rigor was obtained using Lincoln and Guba's [23] criteria . To increase the validity of the data, observation integration, interviewing for data collection, and reflexivity was used throughout the research. The researcher sought to increase the validity of the findings by prolonged and profound involvement with the data and long-term presence in the NICU.

Reliability and validity were determined by triangulation (observation \& interview), reflexivity, Peer Checking, external check and member checking. Reflexivity was attempted in order to reduce the impact of the researcher's viewpoints on data analysis, to reduce the impact of individual values, the PI recorded her thoughts in a diary notes before and during data collection and analysis. Peer Checking was conducted by research team and external checking was conducted by referees of thesis. For member check, the text of the interview, primary codes and main themes were provided to the two nurses, one physician and the two mothers, and they were asked to compare the results of the analysis with their own experiences and provided their opinions.

\section{Ethical considerations}

Ethical approval was granted by the Ethics Committee of Tabriz University of Medical Sciences (Approval IR.TBZMED.REC>2016.789).

\section{Results}

Eighteen nurses, five physicians and twenty-one mothers participated in the study. The demographic characteristics of participants are presented in Table 1. Two hundred and fifty hours of participant observation was undertaken over seven months. Interviews were of 30-60-minute duration. Findings from this study showed that the culture of support in the NICU was one of compassionate support. Two themes emerged from the data: failure to meet the support needs of mothers and provision of support in special circumstances (table 2).

Table 1: Demographic Characteristics of Participant 


\begin{tabular}{|c|c|c|c|c|c|c|c|c|c|}
\hline & \multicolumn{2}{|c|}{ Sex } & \multirow[t]{2}{*}{ Age/year } & \multicolumn{2}{|c|}{ marital status } & \multirow[t]{2}{*}{ Education } & \multirow[t]{2}{*}{ work experience } & \multirow[t]{2}{*}{ Job status } & \multirow[t]{2}{*}{ Shift } \\
\hline & Male & Female & & married & single & & & & \\
\hline physician $(\mathrm{N}=5)$ & 4 & 1 & $(35-45)$ & 5 & 0 & $\begin{array}{l}\text { Neonatal } \\
\text { Specialist }\end{array}$ & $10-25(Y)$ & Official $=5$ & Day $=5$ \\
\hline Nurse $(N=18)$ & 0 & 18 & $24-49$ & 12 & 6 & $\begin{array}{l}\text { Bachelor of } \\
\text { Science }=18\end{array}$ & 1-19(Y) & $\begin{array}{l}\text { Official }=12 \\
\text { Contractual }=6\end{array}$ & $\begin{array}{l}\text { Day }=2 \\
\text { Rotation } \\
=16\end{array}$ \\
\hline \multirow[t]{3}{*}{ Mother $(\mathrm{N}=21)$} & \multicolumn{2}{|c|}{ Number of Child } & \multirow[t]{2}{*}{ Age/year } & \multicolumn{2}{|c|}{ Marital status } & \multirow[t]{2}{*}{ Education } & \multirow{2}{*}{$\begin{array}{l}\text { Duration } \\
\text { of infant hospitalization/ } \\
\text { day }\end{array}$} & \multirow{2}{*}{\multicolumn{2}{|c|}{ Job status }} \\
\hline & Nullipara & Multipara & & married & single & & & & \\
\hline & 16 & 5 & $20-35$ & 21 & 0 & $\begin{array}{l}\text { Primary } \\
\text { education=4 } \\
\text { Secondary } \\
\text { education=11 } \\
\text { Bachelor of } \\
\text { Science }=6\end{array}$ & $7-60$ & $\begin{array}{r}\text { Housewif } \\
\text { Employe }\end{array}$ & \\
\hline
\end{tabular}

Table 2: Primary and Subthemes of Study

\begin{tabular}{|l|l|}
\hline \multicolumn{2}{|c|}{ Table 2: Primary and Subthemes of Study } \\
\hline failure to meet the support needs of mothers & \multicolumn{1}{|c|}{ support in special circumstances } \\
\hline \multicolumn{2}{|c|}{ Subthemes: } \\
\hline Failure to accompany the mother in care & Reassuring the mother \\
\hline Assigning monitoring and care to the mother & Supporting mothers with reduced functional capacity \\
\hline Inadequate Sharing of medical Information & Providing Information \\
\hline
\end{tabular}

\section{Failure to Meet the Support Needs of Mothers}

Data from observations and interviews showed two things. Firstly, that mothers of neonatal babies in the NICU had complex support needs. Secondly, that these support needs were not adequately met. Within this theme of failure to identify and meet the support needs of mothers, three sub themes emerged. 1. Failure of the nurse to accompany the mother in care. 2. Assigning responsibility of care to the mother and 3 . Inadequate sharing of information.

\subsection{Failure to Accompany the Mother in Care}

"I used to say just come and stand with me while I change the nebulizer water or the diaper" (Mother 1)."

"Because I did not know how to breastfeed and was scared to hurt my infant, I asked the nurse, am I caring for my infant properly? (Mother 3)"

Although nurses believed that supporting mothers was necessary, resource constraints, specifically staffing, meant that they did not have the capacity to provide such supportive careOne nurse demonstrates the inner conflict this causes when she says:

"Mothers, especially those who are from the country, are under significant pressure. It is difficult for us to support the mother as well as care for the neonate because we are so busy" (Nurse 14).

\subsection{Assigning Monitoring and Care to the Mother}


"I breast fed my son in the morning and then he went to sleep. Now he won't wake up which is worrying. the nurse told me to knock on his feet to get up, but he fell asleep again. I feel strongly that the nurse must examine my infant. Maybe something has happened to him " (Mother 9).

"When I'm not present, no one cares for my neonate. When I'm asleep, and my infant is crying and waking me up early" (Mother 16).

\subsection{Inadequate Sharing of Medical Information}

Mothers felt that medical staff, specifically physicians, did not spend enough time sharing clinical information. They felt that there was not sufficient time dedicated to answering questions and concerns they had about their infant. Barriers to medical staff not being able to spend time on communication purposes with family appeared to be multi-factorial. For example, lack of medical staff resulting in busy workloads and subsequent prioritization of clinical treatment and training. Physicians appeared to spend most of their time training students due to clinical demands. Sometimes prolonged training and time constraints meant they had to hurry to examine patients. The implication of this was that if a mother had more questions, she would have to wait for the physician to finish medical rounds. One of the physicians said:

"Because after visiting the babies, I have to attend medical student education classes, so I have little opportunity to visiting , so I do not have enough time to answer all the questions of mothers" (physician 3).

Most mothers would seek out the physician when they had finished rounds and were leaving the NICU to have their questions answered. In these instances, the physician's brief answer to posed questions was not satisfactory. For example,

" I show the physician the chest X-ray images and ask for further explanation on my infant's medical condition. The physician responds by simply saying his lungs are infectious. I would expect him to explain more. "(Mother 5).

Most tests are specialized and the mother is not able to understand them, so I do not see the need to explain them in more detail, and as soon as the mother knows there is nothing to worry about. Most tests are specialized and the mother is not able to understand them, so I do not see the need to explain them in more detail, and as soon as the mother knows there is nothing to worry about.

"The mother wants me to interpret the results of the lumbar puncture test. Well, this test is a specialized test. So, I tell the mother that she needs to ask the physician about this specialized test. we do not have the knowledge to interpret findings" (Nurse 14).

"We are told what the neonate's medical problem is. the nurse is not allowed to announce the result of ultrasound. we cannot precisely interpret. it is the physician's duty to interpret the test" (Nurse 3).

\section{Support under Special Circumstances}

As previously described, nurse patient ratios appeared to be significant contributing factor to mothers support needs not being met. High workloads meant they were unable to attend to the mother. However there were some nurses who did provide support for mothers whenever the smallest opportunity presented. These nurses exhibited empathy, kindness and compassion towards mothers. Within this theme of 'support under special circumstances', three sub-themes emerged. 1. Reassuring the mother. 2. Accompanying the mother with reduced functional capacity and 3. Providing information.

\subsection{Reassuring the Mother}

Mothers of neonates who had physical abnormalities (such as hydrocephaly, cleft palate, meningomyelocele) expressed frustration and upset at facing new conditions in care. For example, the method of tying an infant diaper that had undergone bladder exstrophy surgery is different from a healthy infant, so a multipara mother had trouble tying her infant's diaper. In these situations, some nurses offered encouragement and assured the mother that they would support her with care. The following describes an observed moment when a nurse attempts to reassure the mother of a neonate with meningomyelocele.

The mother was crying. Through her tears she asked the nurse how to breastfeed her infant and what to do with her back. The nurse kindly faced the mother and nodded. She responded by saying

"don't worry, I will teach you how to breastfeed. I will tell you what to do. Don't worry and trust in God" (Nurse7).

This nurse identified that mothers needs in that particular moment and subsequently provided her with the help and reassurance she required. Some nurses would advise the mother to rest when she felt tired, assuring her that she would take care of the neonate in her absence whenever they were free.

"I tell the mother that 'I am here for half an hour or an hour. If your infant wakes up, I'll give him milk and wake you up if I need you.' This enables the exhausted mother to rest for half an hour" (Nurse 9).

\subsection{Supporting Mothers with Reduced Functional Capacity}

Some mothers were unable carry out physical cares due to reduced functional capacity. For example, physical function was decreased in mothers who had undergone caesarean sections or had vaginal stitches. In these instances, nurses were required to provide primary care of the neonate.

"Changing a diaper is the duty of the mother but sometimes an ill mother, such as one post caesarean section may not be able to attend to all of her infant's cares. In these cases, our to assist the mother with caring for her infant" (Nurse 13).

Page 5/10 
Post-natal mental health issues such as low mood, depression, anxiety and stress also affected a mother's ability to care for her infant. If depressive symptoms were evident or if a mother was stressed and/or overwhelmed about the clinical condition of her infant, greater support from nurses was required. In these situations, nurses recognized that the mother was struggling and responded by spending more time nursing her infant.

Another example of situations when nurses would provide greater support to mothers was when a mother appeared to have exhausted all options of consoling her upset infant. Often, in these situations the mother was visibly upset. One nurse describes this when she says:

"Most mothers have trouble calming their neonates. They get distressed that their infant will not stop crying. We check to see if the infants upset is due to a dirty diaper or bloating" (Nurse 14).

\subsection{Providing Information}

Overall mothers reported that they were provided with little clinical information regarding treatment and illness. However, there was some satisfaction around communication regarding certain care practices. For example, the mother of a neonate with a cleft palate asked the physician

"Can I give my milk to my infant?" The physician responded by saying "Yes, you can breastfeed, and you have to bend over and your nipples have to fill your infant's mouth. However, if you are unable to do that then alternatively use this bottle." (physician 4)

Sometimes physicians prescribed specialized care to teach mothers by nurses

"The physician told the resident" write teaching chest physiotherapy, strengthening sucking, massaging and feeding gavage to mother by nurses, because we may have to discharge infant with NGT. ." (physicianr 3)

Additionally nurses provided educational guidance when a mother was faced with difficulties in caring for her neonate.

"Our mothers are afraid to give syrup to their babies, so we remind mothers to dilute medications such as multivitamins, keep their heads up, and give them slowly." (Nurse 1)

Interviews with mothers illustrated that Mothers in these instances reported satisfaction with the nurse's education in taking care of her infant. For example, one mother said:

The nurse .. taught me the kangaroo care and massage on the mannequin in the training class "(Mother 9). "I would pour the milk through the tube, the nurses would say add the distilled water and they brought distilled water themselves. "(Mother 10).

\section{Discussion}

Based on the findings of this study, the themes "failure to meet the support needs of mothers" and supporting the mothers in certain circumstances, which will be discussed below.

\section{Failure to Meet the Support Needs of Mothers}

Findings from this study suggest that in an Iranian NICU, mothers support needs are not adequately identified and subsequently their needs are unable to be met. This failure to meet the support needs of mothers is attributed to a multitude of factors namely lack of human resources such as resulting in high patient-to-nurse ratio and a culture of support in caring, so that nurses thought that mothers did not need to receive support in primary care, while Nullipara mothers also had problems in this cares.

\subsection{Failure to Accompany the Mother in the Care}

The Findings of this study showed that, mothers in the neonatal unit have always wanted nurses to monitor their care due to lack of experience with a neonate and their care requirements as well as unfamiliarity with the clinical environment. This is supported by Bruce and colleagues. [24] Who assert that mothers feel significant pressure when taking care of their neonates and they therefore need ongoing communication with the nurse as well as a collaborative care approach. Mothers needs for support and guidance from nurses is great and it varies at different stages of their journey [25]. Both Mok [26] and Abuidhail [27] identify considerable gap exists between the level of expected support and the actual support received by mothers. In both these studies mothers felt that they were not supported by the healthcare team.

\subsection{Assigning Monitoring and Care to the Mother}

The present study showed that NICU nurses relied heavily on maternal presence to monitor and care for the infant. This practice where primary care is the responsibility of the mother meant nurses work focused on complex clinical task delivery and overall supervision. Nurses appeared to hold the belief that the mother was primarily responsible for care, however this conflicted with their professional responsibilities; nurses are ultimately responsible for care and while supporting the mother with learning new parenting skills.

The findings of dependence on maternal presence and nurses' primary focus being on technical tasks and interventions is consistent with other studies exploring Iranian NICU nurses practice $[28,29]$. However, what this suggests is that the scope of nursing assessment, care planning and delivery is arguably narrow. Restricting nursing practice to tasks and interventions limits the ability of whole of person and family-centered care to be delivered.

Page $6 / 10$ 
In this context, Aein et al. [30] suggest that nursing focus on technical tasks is attributed to a shortage of nurses. Due to staffing ratios and high patient loads, nurses do not have the time to support and engage in effective, meaningful communication with parents

\subsection{Inadequate Sharing of Medical Information}

The findings from this study showed that mothers did not receive adequate information regarding their infant's clinical condition. Both medical and nursing staff did not appear to priorities spending time on communication purposes and sharing of information. It was considered by both medical and nursing staff a medical responsibility to discuss clinical details.

\section{Supporting Mothers in Certain Circumstances}

The findings of this study showed that nurses were not indifferent to the emotional stresses of mothers. There were times when emotional support was provided, such as when mothers were unable to cope due to reduced physical function or poor post-natal mental health. Mothers who exhibited low mood, anxiety, acute stress and grief received a greater amount of emotional support from nurses.

\subsection{Reassuring the Mother}

\subsection{Supporting mothers with reduced functional capacity}

The present study showed that nurses would not compel the mother to take care of the neonate if she was unsatisfied with the physical and/or mental condition of the mother or would assist the mother if she had a problem with care. Care support has also been confirmed in other studies in Iran. In the study of Mehdizadeh (2017), Seeydamini (2011) and Valizadeh (2010), the most support provided to mothers was in the care dimension [15, 48, and 49]. It seems that because the care of the infant is the responsibility of the nurse, so support in care is the most support for nurses.

\subsection{Providing Mother-Centered Care Information}

In the current study, most of the information provided by the NICU staff to mothers centered on neonate care. Content was specifically focused on aspects of care mothers needed to provide as opposed to clinical information. Mothers expressed a desire for greater clinical information. The results of this study showed that nurses played an effective role in mothers, which provides an opportunity for mothers to participate in this care. Mothers' education is a vital component of family-centered care [50]. According to previous studies, mothers' education has a supportive role for nurses [51] and without education and exchange of information, participation is impossible [52]. Educating mothers about infant care techniques reduces mothers' fears about care and increases their participation [53]. In the Brach study, parental education also increased parents' ability to solve problems and their mental readiness to care for their infants at home [54].

One study in Iran showed the highest levels of perceived nursing support among the mothers of infants with congenital anomalies were related to the communicational-informational [42]. The previous studies showed that providing information to mothers in the intensive care unit leads to increased trust and participation of mothers $[55,56]$.

\section{Limitation:}

In this study, it was not possible to evaluate fathers' support experiences due to the lack of continuous presence of fathers.

\section{Conclusion}

The present study showed that in the intensive neonatal unit, nurses' care is patient-centered and support for mothers involved in the infants' care is not always provided by nurses as one of the main principles of family-centered care. In this study, although most staffs considered maternal support a necessity, they often confirmed the problem of maternal support in the unit and cited workload as a barrier to maternal support. This study declared that the mothers were supported by the staff, particularly while mothers were in serious need of support. However, the staff considered the treatment and care of the infant as their main professional duty and mothers support was provided when they had the opportunity to support.

In this study, manpower shortage was recognized as one of the most important barriers to maternal support, so it is necessary for nursing planners to provide adequate manpower in NICUs.

\section{Abbreviations}

NICU: Neonatal intensive care unit; FCC: Family-centered care;

\section{Declarations}

\section{Acknowledgment}

This paper is part of a PhD dissertation titled "The Neonatal Ward Culture in Collaborative Maternal Care." Authors' sincere appreciation goes to the all research participants and Tabriz University of Medical Sciences. 
The data that support the findings of this study are available from the corresponding authors upon reasonable request.

\section{Authors' contributions}

$\mathrm{MJ}$, the corresponding author, PhD, and Assistant professor of Nursing, designed the study, data collection, interpreted the results and revised the manuscript. The first author, namely, RN, played a role in study conception and design, analysis and interpretation of the data and in preparing and drafting the manuscript, and $\mathrm{HH}, \mathrm{MA}$ and $\mathrm{AB}$ Participated in the design of the study, and interpretation of the data and critical revision of the paper. All authors listed on the manuscript, approved the submission of this version of the manuscript and take full responsibility for the manuscript.

\section{Funding}

No Funding

\section{Ethics approval and consent to participate}

Ethical approval was granted by the Ethics Committee of Tabriz University of Medical Sciences (Approval IR.TBZMED.REC>2016.789). All authors have signed written informed consent and approved the submission of this version of the manuscript and take full responsibility for the manuscript. The legal guardian of all participants signed an informed consent form that their data could be used for various clinical studies.

\section{Consent for publication}

Not Applicable.

\section{Competing interests}

No financial or nonfinancial benefits have been received or will be received from any party related directly or indirectly to the subject of this article.

\section{Author details}

${ }^{1}$ PhD (Nursing), Professor, Nursing and Midwifery Care Research Center, Tehran University of Medical Sciences, Tehran, Iran. No.2 PhD (Nursing), Professor, Center of Qualitative Studies, Department of Medical Surgical Nursing, School of Nursing and Midwifery, Tabriz University of Medical Sciences, Tabriz, Iran.No.3, PhD (Nursing), Assistant Professor, School of Nursing and Midwifery, Tabriz University of Medical Sciences, Tabriz, Iran. No.4, PhD (Sociology), Professor, Department of Sociology, university of University, Tabriz, Iran. No. 5, RN, MN, Campus Teacher, School of Nursing, Massey University, Wellington Campus

\section{References}

1. Jaberi Z, Gholami-Fesharaki M, Rahmati-Najarkolaei F, Saburi A. Mortality rate of one neonatal intensive care unit in Tehran, Iran. J clin Neonatol. 2013; 2(1):52.

2. Hatfield NT. Broadribb's introductory pediatric nursing. Lippincott Williams \& Wilkins; 2007.

3. Masumo M, Mwape L, Katowa-Mukwato P, Maimbolwa M, Chirwa E. Perception of stressors by mothers with babies admitted to the neonatal intensive care unit in women and new born hospital, Lusaka, Zambia. Int J Nurs and Mid. 2019; 11(4): 25-31.

4. Ong SL, Abdullah KL, Danaee M, Soh KL, Soh KG, Japar S. Stress and anxiety among mothers of premature infants in a Malaysian neonatal intensive care unit. J Reprod Infant Psychol. 2019; 37(2):193-205.

5. Heydarpoor Damanabad Z, Valizadeh L, Mansouri Arani M, etal. Evaluation of Maternal Anxiety in Mothers of Infants Admitted to the Neonatal Intensive Care Unit. Int J Pediatr. 2019; 7(10):10215-24.

6. Aagaard H, Hall E. Mothers' Experiences of Having a Preterm Infant in the Neonatal Care Unit: A MetaSynthesis. J Pediatr Nurs. 2008; $23(3): 26-36$.

7. Nazari R, Moradi Koosha F, Rezaie S, Akbari N, Qolizadeh A, Sabzi Z. Experiences of the mothers of infants hospitalized in the neonatal intensive care unit (NICU). J Neonatal Perinatal Med. 2020 (Preprint):1-9.

8. Baughcum AE, Fortney CA, Winning AM, Dunnells ZD, Humphrey LM, Gerhardt CA. Healthcare satisfaction and unmet needs among bereaved parents in the NICU. Adv Neonatal Care. 2020; 20(2):118-26.

9. Obeidat HM, Bond EA, Callister LC. The parental experience of having an infant in the newborn intensive care unit. J Perinat Educ. 2009 ; 18 (3):23.

10. Gutiérrez SS, García PE, Prellezo AS, Paulí LR, Del Castillo BL, Sánchez RB. Emotional support for parents with premature children admitted to a neonatal intensive care unit: a qualitative phenomenological study. Turk J pediatr. 2020; 62(3):436-49.

11. Akbari V, Asayesh H, Hoseini MH, Fard FS, Shahidi M, Goudarzi M. Needs of Family with Hospitalized Infant in Neonatal Intensive Care Unit: A Comparison between Mothers' and Nurses' Viewpoint. Q Uni Med Sci J. 2020; 14(3):10-8.

12. Mousavi SS, Chaman R, Khosravi A, Mohagheghi P, Mousavi SA, Keramat A. The needs of parents of preterm infants in Iran and a comparison with those in other countries: a systematic review and meta-analysis. Iran J Pediatr. 2016; 26(5).

13. Kohan M, Borhani F, Abbaszadeh A, Sultan Ahmadi J, Khajehpoor M. Experience of Mothers with Premature Infants in Neonatal. J Qual Res Health Sci. 2012; 1(1):41-51. 
14. Alinejad-Naeini M, Peyrovi H, Shoghi M. Emotional disorganization: The prominent experience of Iranian mothers with preterm neonate: A qualitative study. Health Care Women Int. 2020; 31:1-21.

15. Mehdizadeh S, Abbasi S, Payami BM. Nursing support and prematures infants in neonatal intensive care units: The views of mothers. The J Urmia Nurs Midwifery Fac. 2017; 6(2): 231 -38.

16. Hill C, Knafl KA, Santacroce SJ. Family-centered care from the perspective of parents of children cared for in a pediatric intensive care unit: an integrative review. Paediatr Nurs. 2018;41:22-33.

17. Cockcroft S. How can family centred care be improved to meet the needs of parents with a premature baby in neonatal intensive care? J Neonatal Nurs. 2012;18(3):105-10.

18. Yu X, Zhang J, Yuan L. Chinese Parents' Lived Experiences of having Preterm Infants in NICU: A Qualitative Study. J Pediatr Nurs 2020;50:e48-54.

19. Cleveland LM. Parenting in the neonatal intensive care unit. J Obstet Gynecol Neonatal Nurs. 2008;37(6):666-91.

20. Ichijima E. Nursing Roles in Parental Support: A cross-cultural comparisons between Neonatal Intensive Care Units in New Zealand and Japan.2009;thesis.

21. Malakouti J, Jebraeili M, Valizadeh S, Babapour J. Mothers' experience of having a preterm infant in the Neonatal Intensive Care Unit, a Phenomenological Study. J Crit Care Nurs. 2013;5(4):172-81.

22. Roper JM, Shapira J. Ethnography of nursing resarch: SAGE Publications Inc. United States. 2000.

23. Guba EG, Lincoln YS. Competing paradigms in qualitative research. Handbook of Qualitative Research. 1994;2(163-194):105.

24. Bruce E, Lilja C, Sundin K. Mothers' lived experiences of support when living with young children with congenital heart defects. J Spec Pediatr Nurs. 2014;19(1):54-67.

25. Skene C, Franck L, Curtis P, Gerrish K. Parental involvement in neonatal comfort care. J Obstet Gynecol Neonatal Nurs. 2012;41(6):786-97.

26. Mok E, Leung SF. Nurses as providers of support for mothers of premature infants. J Clin Nurs. 2006;15(6):726-34.

27. Abuidhail J, Al-Motlaq M, Mrayan L, Salameh T. The lived experience of jordanian parents in a neonatal intensive care unit: A phenomenological study. J Nurs Res.2017;25(2):156-62.

28. Salmani N, Dabirifard M, Maghsoudi Z, Dabirifard A, Karjo Z. Comparing perception of nurse-mother communication between neonatal intensive care nurses and mothers of hospitalized neonates. J hayat. 2016;22(3):291-9

29. Sepehri Nia M, Rassouli M, Alaee Karahroudi F, Zayeri F, Zagheri Tafreshi M. Comparing perception of nurse-mother communication between nurses and mothers' hospitalized children. Q J Nurs Manag. 2013;2(3):52-9.

30. Aein F, Alhani F, Mohammadi E, Kazemnejad A. Parental participation and mismanagement: a qualitative study of child care in Iran. J Nurs Health Sci. 2009;11(3):221-7.

31. Bhandari N, Shrestha S, Dongol S, Bal B. Perception of mothers needs and nurses felt needs on nursing care provided by nurses to their neonates in the neonatal intensive care unit. J Coll Med Sci. 2017;13(4):406-9.

32. De Bernardo G, Svelto M, Giordano M, Sordino D, Riccitelli M. Supporting parents in taking care of their infants admitted to a neonatal intensive care unit: a prospective cohort pilot study. Ital J Pediatr. 2017;43(1):36.

33. Rasti M, Aliabadi F, Shafarodi N, Rafiee F, Kalani M. Specification of the educational needs of parents with premature infants admitted to neonatal intensive care unit. J Mod Rehabil. 2014;8(4):21-9.

34. Heidari H, Hasanpour M, Fooladi Stress Management among parents of neonates hospitalized in NICU: A qualitative study. J Caring Sci. 2017; 6(1): 29-38.

35. Mirjalili M, Azizzade forouzi M, Sabzevari S, heidarzadeh A, Haghdost A. Assess the admission needs of the mothers of hospitalized in the neonatal intensive care unit. Iran J Pediatr Nurs. 2015;2(2):1-9.

36. Obeidat HM, Bond EA, Callister LC. The parental experience of having an infant in the newborn intensive care unit. J Perinat Educ. 2009;18(3):23.

37. Davidson JE, Aslakson RA, Long AC, Puntillo KA, Kross EK, Hart J, et al. Guidelines for family-centered care in the neonatal, pediatric, and adult ICU. Crit Care Med. 2017;45(1):103-28.

38. Hallowell SG, Rogowski JA, Lake ET. How nurse work environments relate to the presence of parents in neonatal intensive care. Adv Neonatal Care. 2019;19(1):65-72.

39. Khademi M, Mohammadi E, Vanaki Z. Resources-tasks imbalance: Experiences of nurses from factors influencing workload to increase. Iran J Nurs Midwifery Res. 2015;20(4):476.

40. Turner M, Chur-Hansen A, Winefield H. The neonatal nurses' view of their role in emotional support of parents and its complexities. $\mathrm{J}$ Clin Nurs. 2014;23(21-22):3156-65.

41. Seyedrasooli A, Malakouti J, Jabraeili M, Heykalabadi S, Ghogazadeh M. The effect of the supportive program on the anxiety of mothers of infants with gastrointestinal anomalies. Nurs Pract Today. 2020; 7,( 2): 106-113.

42. Jabraeili M, Arshadi M, Namdar H, Ghojazadeh M, Jafarpour Z, Najafi F. Correlation of perceived nursing support with stress and self-confidence among the mothers of infants with congenital gastrointestinal anomalies. Nurs Midwifery Stud. 2018;7(4):163-7.

43. Wigert H, Dellenmark MB, Bry K. Strengths and weaknesses of parent-staff communication in the NICU: a survey assessment. BMC pediatr. 2013;13(1):71. 
44. Ahmadi z, joz mohtashami M, Seyed Fatemi N, Haghani H. Study of realationship between social support and parents satisfaction of provided care for premature infants in selected hospitals of Tehran University of Medical Sciences. Iran J Pediatr Nurs. 2015;2(2):39-48.

45. Gaucher N, Nadeau S, Barbier A, Payot A. Antenatal consultations for preterm labour: how are future mothers reassured? Arch Dis Child Fetal Neonatal Ed. 2018;103(1):F36-F42.

46. Fenwick J, Barclay L, Schmied V. Interactions in neonatal nurseries: women's perceptions of nurses and nursing. J Neonatal Nurs (Lond). 2000;6:197203.

47. Russell G, Sawyer A, Rabe H, Abbott J, Gyte G, Duley L, et al. Parents' views on care of their very premature babies in neonatal intensive care units: a qualitative study. BMC Pediatr. 2014;14(1):230.

48. Seyedamini B. Fears, Needs and Nursing Support of Mothers during Their Child's Hospitalization. Iran J Nurs. 2011;24(72).

49. Valizadeh L, Akbarbegloo M, Asadollahi M. Supports provided by nurses for mothers of premature newborns hospitalized in NICU. Iran J Nurs. 2009;22(58):89-98.

50. Bracht M, O'Leary L, Lee SK, O'Brien K. Implementing family-integrated care in the NICU: a parent education and support program. Adv Neonatal Care. 2013;13(2):115-26.

51. Al-Akour NA, Gharaibeh M, Al-Sallal RA. Perception of $\mathrm{J}$ ordanian mothers to nursing support during their children hospitalisation. $\mathrm{J}$ clin Nurs. 2013;22(1-2):233-9.

52. Vasli P, Salsali M, Tatarpoor P. Perspectives of nurses on barriers of parental participation in pediatric care: A qualitative study. J hayat. 2012;18(3):2232.

53. Salimi T, Khodayarian M, Bokaie M, Antikchi M, Javadi S. Mothers' experiences with premature neonates about Kangaroo care: Qualitative approaches. Int J Pediatr. 2014;2(1):75-82.

54. . Bracht M, O'Leary L, Lee SK, O'Brien K. Implementing family-integrated care in the NICU: a parent education and support program. Adv Neonatal Care. 2013;13(2):115-26.

55. Alaee Karhrouy F, Jafari Mianaie S, Rassouli M, Zayeri F. Evaluating the effectiveness of Parent Empowerment (COPE) program on participation of mothers of preterm infants hospitalized in NICUs of hospitals affiliated to Isfahan University of Medical Sciences and Health Services, 2009-2010. J Shahid Behesh Sch Nurs Midwifery. 2014;23(81):55-65.

56. Cooper L, Gooding J, Gallagher J, Sternesky L, Ledsky R, Berns S. Impact of a family-centered care initiative on NICU care, staff and families. J Perinatol 2007;27(S2):S32. 